\title{
Expansive Research into How to Improve Library Intelligence Ability and Methods in Big Data Era
}

\author{
Gemin Li \\ Library, Jilin Agricultural University, Changchun, 130118 \\ 308420502@qq.com
}

Keywords: Big data; Library intelligence; Ability; Path; Expansion

\begin{abstract}
The emergency of the digital network era has promoted the development of library intelligence, and corresponding research fields are being constantly expanded while its academic and social value are gradually embodied. Thus, to carry out knowledge service has become an inevitable road for library intelligence to adapt to the development of knowledge economy. In the big data era, to improve the efficiency of library information ability can effectively improve the intelligence body single text to obtain useful information, clarify the trend, mutate corresponding policies, the author explains the library and information service, and explore how to impro forve the intelligence ability and expand channels of books.
\end{abstract}

\section{Introduction}

Library intelligence related work is mainly associated with library and information analysis, library science is also the subject about library business, and intelligence science is a subject about intelligence information aiming at the storage, organization, search, consulting and analysis of literature information, etc. In order to adapt to the urgent demand for professional library intelligence talents due to the development of library intelligence cause in the new situation, improve library intelligence talent cultivation system and innovate library intelligence talent cultivation mode, improve the quality of library intelligence talents, China begins to set professional master's degree in library intelligence, thus it can be seen the importance of library intelligence work. In the specific work, the book information is more focused on the acquisition of information, not only confined to books and related content, but also more important is the information finishing, competitive information, management consulting and market forecasts, etc.. Who can grasp the first books information accurately in the vast information, timely access to first-line information, who will be able to gain a foothold in the competition, the correct decision is very important for the long-term development of the main unit of the. The era of big data is information explosion to be processed by the existing software, big data is actually a way to solve the problem, through the mainstream platform for large-scale statistical data, the results will be timely sent to the decision-makers, let the decision makers to obtain valuable content.

\section{Library Intelligence Work}

Tentative Exploration of Library Intelligence Practice. First, information resource construction. The so-called information resources are a collection of all the information that people have to be developed and owned, which is composed of information, human, symbol and carrier. Through the construction of resources, people will have no organization of all kinds of information to integrate the development and use of information resources, there are three categories, the literature of information resources, digital information class, virtual information class. Especially for the relevant departments of the library and information, through a specific goal, by means of coordination, the relevant information required document collection, organize the information resources service system to form high safety, so need the main unit of the readers and the society the user can timely query. For the library and information field, the construction of information resources is of great significance, it is the prerequisite for the smooth development of all library and information work. 
Second, improve scientific and technological intelligence system ability. Through public welfare scientific research institutions, innovation mechanism, relevant scientific and technological management department makes scientific and technological intelligence system serve for economic and social progress and constantly improve the scientific and technological intelligence system's ability. Scientific and technological information institutions have important roles in the construction of literature resources, information research and technical development of the country. To improve the ability of scientific and technical information system is to improve the ability of decision making, quick response and cooperative work.

Main Business of Library Intelligence Work. First, provide services to government departments. First of all, library intelligence provides decision-making basis for local scientific planning, regional economic and social development and the proposition of relevant measures with great significance on government departments' research into intelligence. Second, according to requirements of economic and scientific development, improve the information value of "Scientific Information Reference". Third, fully utilize library intelligence work to promote science and technology so as to contribute to scientific progress of each region, make farmers master science and technology and promote agricultural production.

Second, to provide documents and services for the development of society, open library collections, data resources and other documents to the community. In addition, the library and information processing to meet the public's demand for high quality information.

Third, Provide services for individual education and group personnel training. According to the requirements of the development of social science and technology, the needs of individuals or groups to train the extreme and professional qualification certificate, etc., mining information training market. Advocating lifelong information education for the whole people.

Fourth, set up scientific and technological service platform. Library and information institutions can build scientific and technological innovation platform for the needs of people at any time to find information on the network platform, the effective implementation of resource sharing, platform docking, to achieve national scientific and technological information innovation strategy.

\section{Improve Library Intelligence Ability}

Use multi-dimensional qualitative analysis. The concept of dimension is a set and space theory, which belongs to the space structure. The qualitative analysis is through the use of abstraction and generalization, analysis and synthesis, induction and deduction and comprehensive information for continuous processing, understanding the essence through the appearance, found the original appearance of things, find things works. Library information can be viewed as a comprehensive practice space and multi-dimensional space, with spatial dimensions as the starting point, including the expansion of library information and the number of public library book sales information attention, on the books of the scope of knowledge. The time dimension is a vertical development process. In this way, from the multi-dimensional analysis of library information, coupled with qualitative research methods, to infer the information and the development of the information content. The use of the time dimension can be effective analysis of library related information during the whole development, development through comparative study of various professional college to learn, and then through the comparison of college students to borrow a library, can reflect the University City Economic Development and the social science and technology trends. Finally, the overall sales volume of books from the major bookstores in this dimension can reflect the reader or the reader's reading interest, reading at a time in a set point, reflecting the social knowledge of hot issues. From the dimension of library knowledge growth, it can reflect the development of a certain range of knowledge, reflecting the trend of a professional development and the current hot spots. All in all, the concept of the dimension can be used to study the development of books, to predict the future direction of the development of knowledge, and to improve the ability of Library and information in this area.

Multidimensional cross fuzzy qualitative analysis. Multi-dimensional precision cross analysis can be used to learn a certain range of Library and information content. The use of qualitative 
research methods can effectively discover the development trend of the library on a certain dimension level to get the relevant information. Knowledge in order to obtain the library information can only be based on the dimension of the level of evaluation and cannot be accurately aimed at a certain dimension value analysis, that is, the characteristics of the emergence of fuzzy. It can be concluded that the fuzzy features in the scope of these dimensions can be obtained under the multi dimension cross environment. But how to make the fuzzy feature into a clear content, so that users need to get the information content of the book is the focus of research.

Big data quantitative analysis. Quantitative analysis is the analysis object of quantitative analysis, the research objects are the number of what kind of relationship between the elements, or what is the relationship between the number of its nature, can also be between several objects, etc., to quantify the analysis results. In the new era of the development of science and technology, big data is the representative of the development of Library and information science and technology, it is the combination of structured and unstructured data, with a huge amount of data. Big data processing method is to help users to search, query, analysis, mining massive data in the complex, useful information on their own resources and find a lot of information, the library is a collection of body, need the help of big data techniques, analysis books information, readers borrow time, loan interest, and focus on the development of professional knowledge, improve information collection ability. For improving the ability of Library and information technology, big data technology is not no way, is an effective growth pole. The number of the number of books from the first book purchased, can be drawn in the important content of a certain period of time the readers concerned, so as to analyze the popular readers and focus on Library and information needs, understand the different types of professional books and popular history books intelligence knowledge degree. In addition, through the analysis of the open library information, it is concluded that the social reader's attention to the knowledge information is obtained through quantitative analysis. Similarly, in the University, students can understand what professional books of interest through quantitative data analysis methods, to provide reference for the purchase of books from the library, on the whole, can also understand the trends of students' reading professional colleges and universities at home and abroad, and the development direction of library, to seek further development of useful strategies.

\section{Expand Library Intelligence Paths}

The use of a new generation of information technology. Today's information technology represents a big data, networking and cloud computing technology, such as the use of this new technology to help expand the new ways of Library information. At present, more readers prefer to read on the mobile device, which can save time, but also provide convenience to read at any time, access to knowledge. The electronic digital library can help readers in the use of network channels, many universities have their own electronic reading room, which is convenient for students to acquire knowledge from the network, books can provide time limited knowledge. How to enhance the library information ability is very important in this case, using the latest information technology continue to dig out the useful information in the mass data, analyzed and refined, in order to find useful for Library and information content of the main body. These valuable books and information are often hidden in a large number of data information, the need to use advanced means to dig. From the angle of information acquisition, analysis and processing of a large amount of information on the value of the information is not formatted, stored in order to prepare for the use of. Through the introduction or training of Library and information technology personnel, and constantly improve the main unit of the work of the library intelligence.

The normal way to expand the ability of Library and information. Library and information related to the meeting, the annual analysis of the book data, or the various libraries on the work of Library and information related to the exchange and communication. This will be able to timely access to domestic and foreign library and information resources, the effective analysis of the book information, to get valuable information. The yearbook data analysis can give information to provide valuable data for reference, by means of quantitative and qualitative analysis, can learn about the current development trend of Library and information, a solid foundation for improving 
the book information ability, the first time to grasp the rich information of Library and information channel.

\section{Conclusions}

In the big data era, the rapid development of science and technology needs to constantly improve library intelligence ability, and it can also help relevant departments and units to obtain the true and accurate library intelligence immediately, and master the development trend of library intelligence. The author discusses relevant contents of library intelligence and then proposes to use multi-dimensional analysis and cross puzzle qualitative analysis to improve library intelligence ability, and also studies ways to expand and improve library intelligence ability.

\section{References:}

[1] Li Rongshan, Wu Xinwen, Liang Jingyan, etc. Modern Information Transmission [M]. Wuhai, Hubei People's Press, 2004:3-6.

[2] Zhang Huaitao, Suo Chuanjun, Dai Genxing. Network Environment and Library Information Resources [M]. Zhengzhou: Zhengzhou University Press, 2002: 119-123.

[3] Liang Zhanping. Reflections on Innovating and Developing Intelligence Science [J]. China Information Guide, 2007(1): 6-7.

[4] Wu Weici. Development report of philosophy and Social Sciences in Chinese universities (1978-2008). Guilin: Guangxi Normal University press, 2008

[5] Zhang Shuhua, Zhang Jiuzhen, etc. China's Library Cause Since the 20th Century. Beijing: Beijing University Press, 2008.

[6] Yang Peichao. Research into the Development of China's Library Intelligence Cause [M]. Beijing: National Library Press, 2010.

[7] Cheng Huanwen. Century's History and a New Chapter - Retrospect of China's Library Cause in the 20th Century and Prospect [J]. Library Construction, 2004: 1-8.

[8] Liu Jia, Fan Bingsi. Library Intelligence in the Era of Social Reform, Subject Development in 1992-1993 [J]. Library Magazine, 1994 (1): 16-21.

[9] Fan Bingsi, etc. Western and Chinese Library in the 20th century-- Based on Delphi method evaluation theory of [M]. Beijing: Beijing Library Press, 2004

[10]Huo Guohua. Century's Vicissitudes - General history of Library Science in twentieth Century Chinese mainland and Taiwan area [J]. Library, 1998(3):1-9.

[11]Guo Zikuan, etc. Application of Big Data Ecological System in Library [J]. Intelligence Material Work, 2013,(2):23-28. 